Supporting Information

\title{
Evaluation of PolyMPC-Dox Prodrugs in a Human Ovarian Tumor Model
}
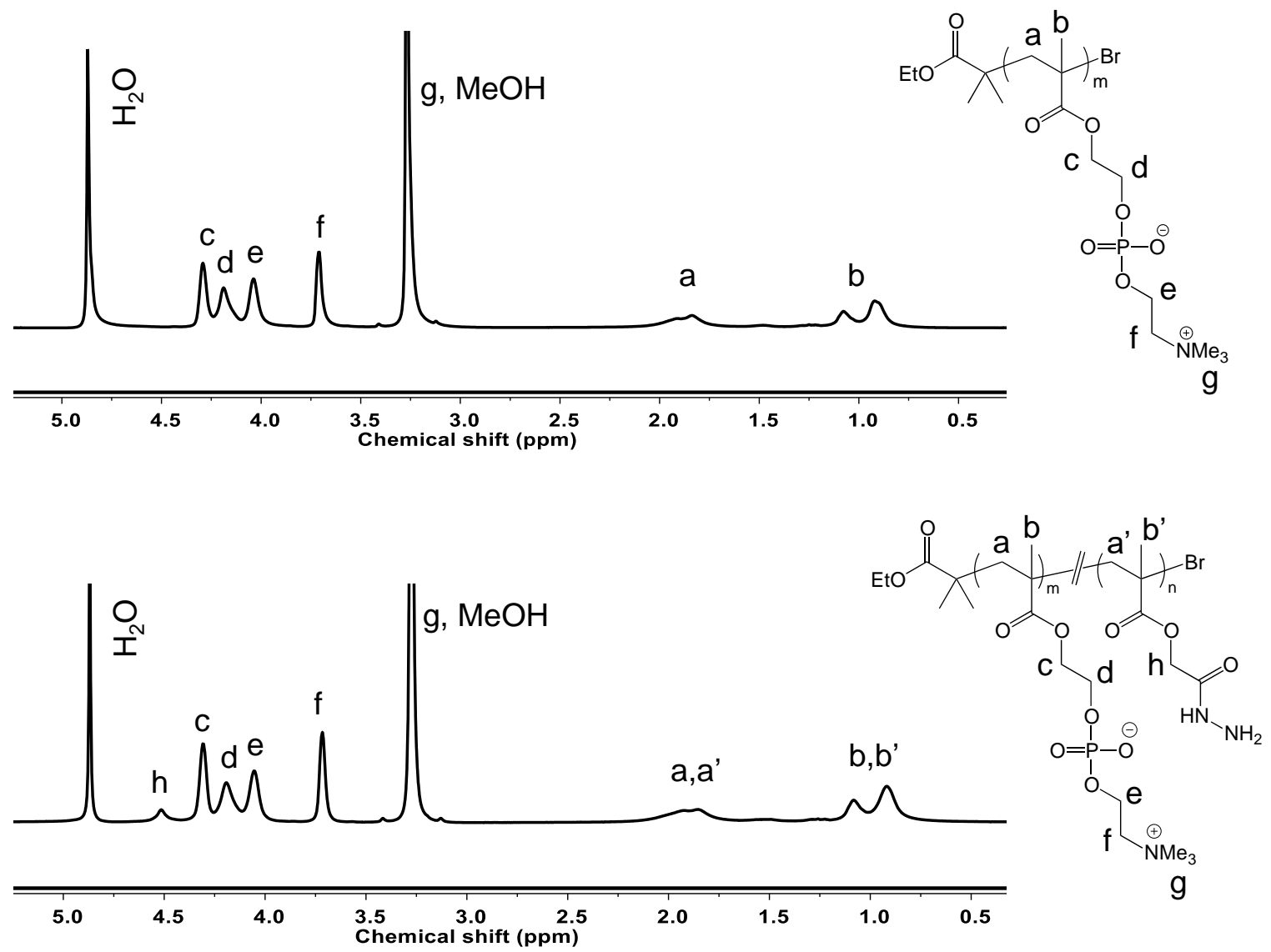

Figure S1. ${ }^{1} \mathrm{H}-\mathrm{NMR}(500 \mathrm{MHz})$ spectra of polymer 1 (top), and polymer 2 (bottom) in MeOD-D 4 . 
A)

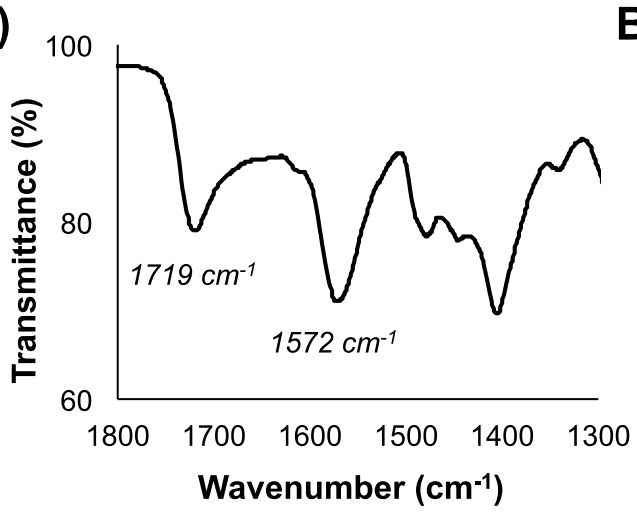

C)

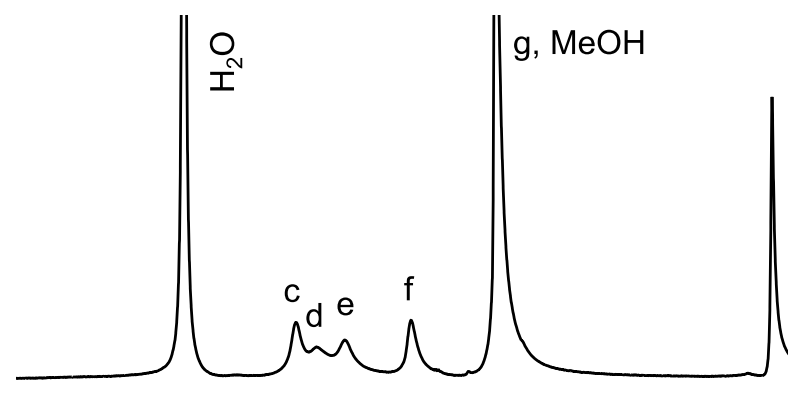

B)

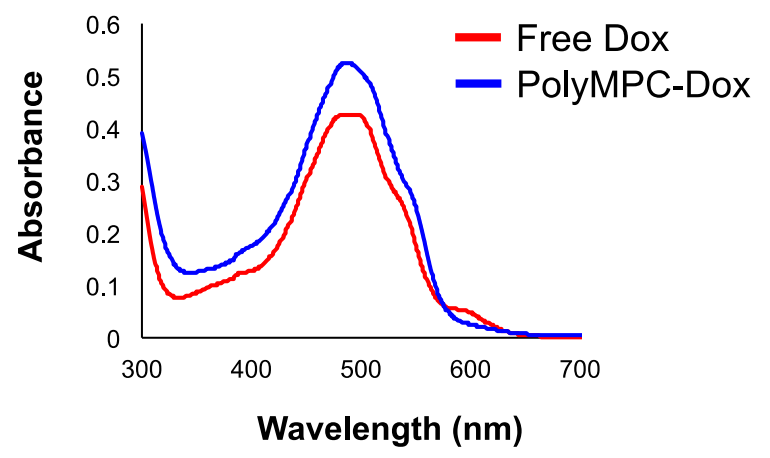

$a, a^{\prime} \quad b, b^{\prime}$

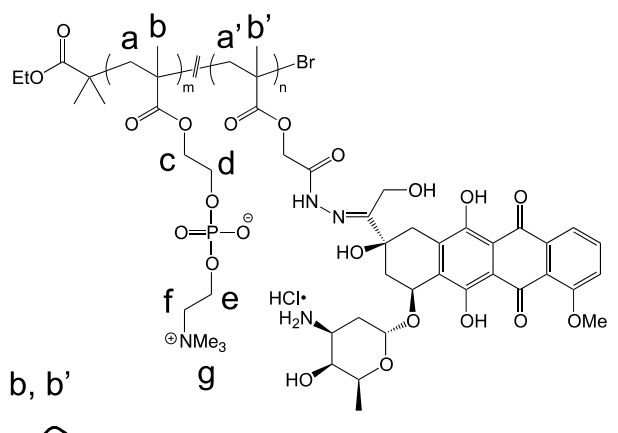

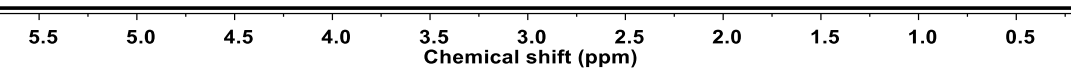

Figure S2. Spectroscopic characterization of polyMPC-Dox 3: A) IR spectrum showing signals at 1719 and $1572 \mathrm{~cm}^{-1}$ for the $\mathrm{C}=\mathrm{O}$ and $\mathrm{C}=\mathrm{N}$ stretching of the methacrylate esters and hydrazones, respectively; B) UV-Vis absorbance spectra of free Dox $(0.05 \mathrm{mg} / \mathrm{ml})$ and $3(0.25 \mathrm{mg} / \mathrm{ml})$ in pure water; C) ${ }^{1} \mathrm{H}-\mathrm{NMR}(500 \mathrm{MHz})$ spectrum of $\mathbf{3}$ recorded in MeOD-d . $^{2}$ 

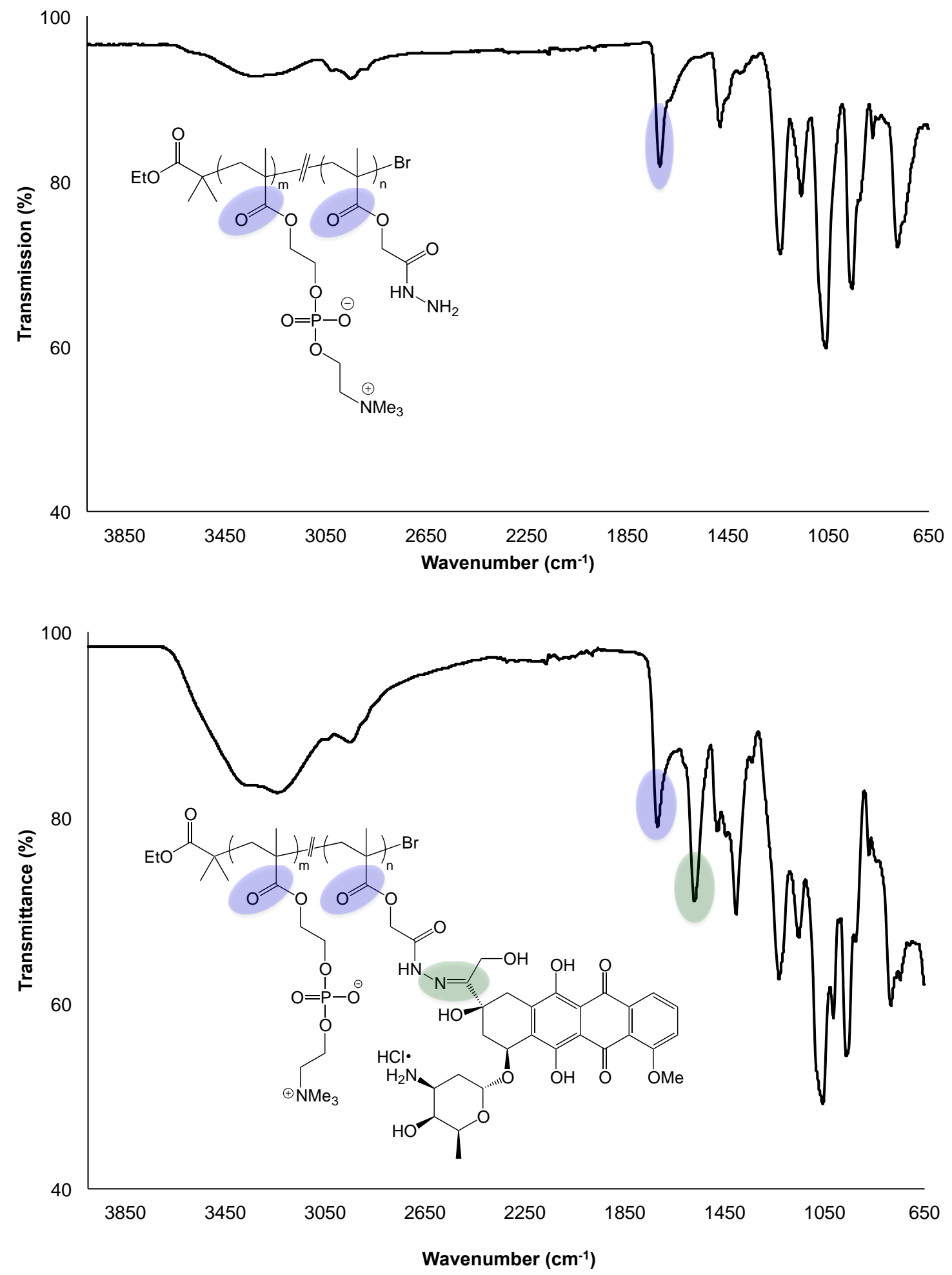

Figure S3. IR spectra of polymer 2 (top), and polyMPC-Dox 3 (bottom). Following Dox conjugation, a new peak in the IR spectrum of 3 at $1572 \mathrm{~cm}^{-1}$ is observed that is attributed to the $\mathrm{C}=\mathrm{N}$ stretching of hydrazone linkages. 


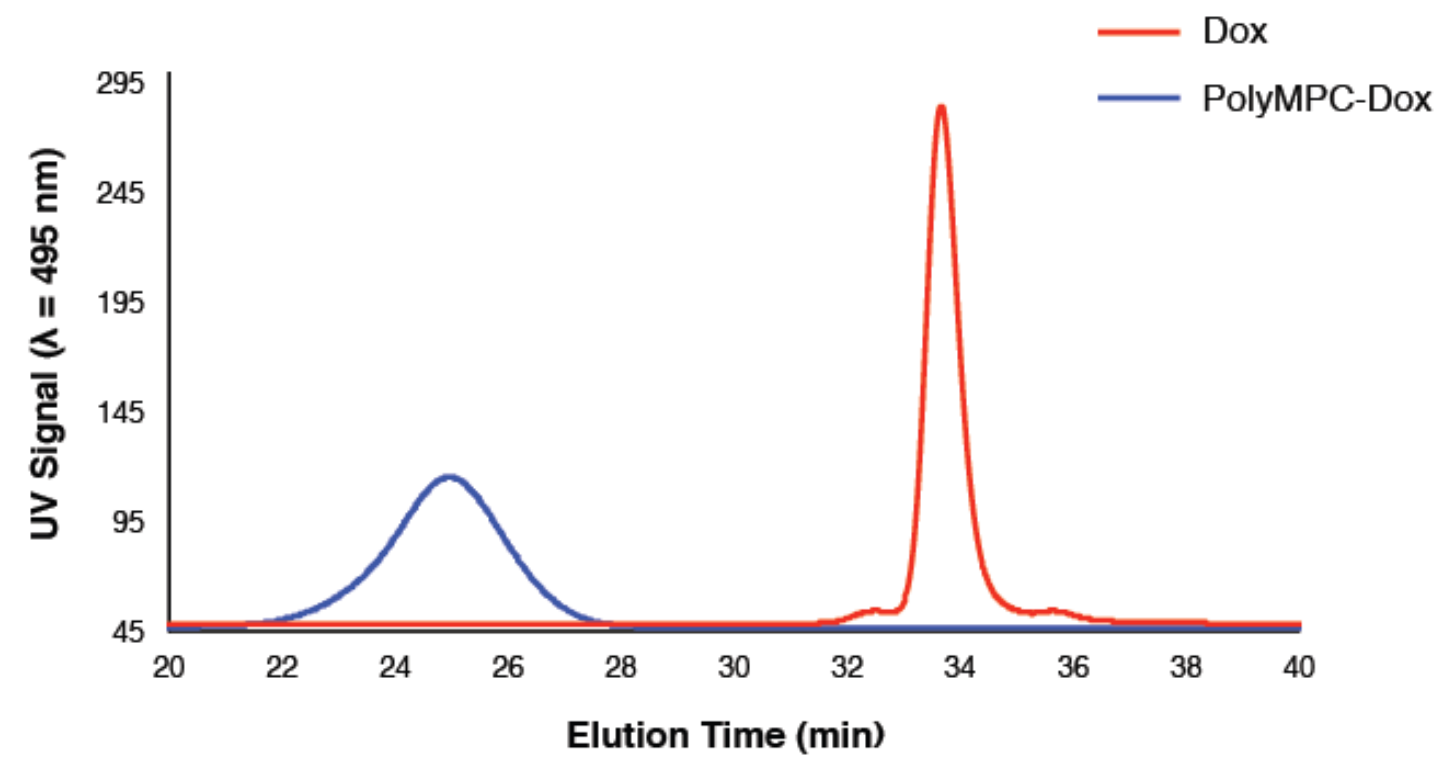

Figure S4. GPC chromatograms (eluting in trifluoroethanol) of Dox and polyMPC-Dox prodrug 3. For prodrug 3 , a single polymer fraction was observed (24.8 minutes), with a notable absence of any residual Dox (33.6 minutes). 

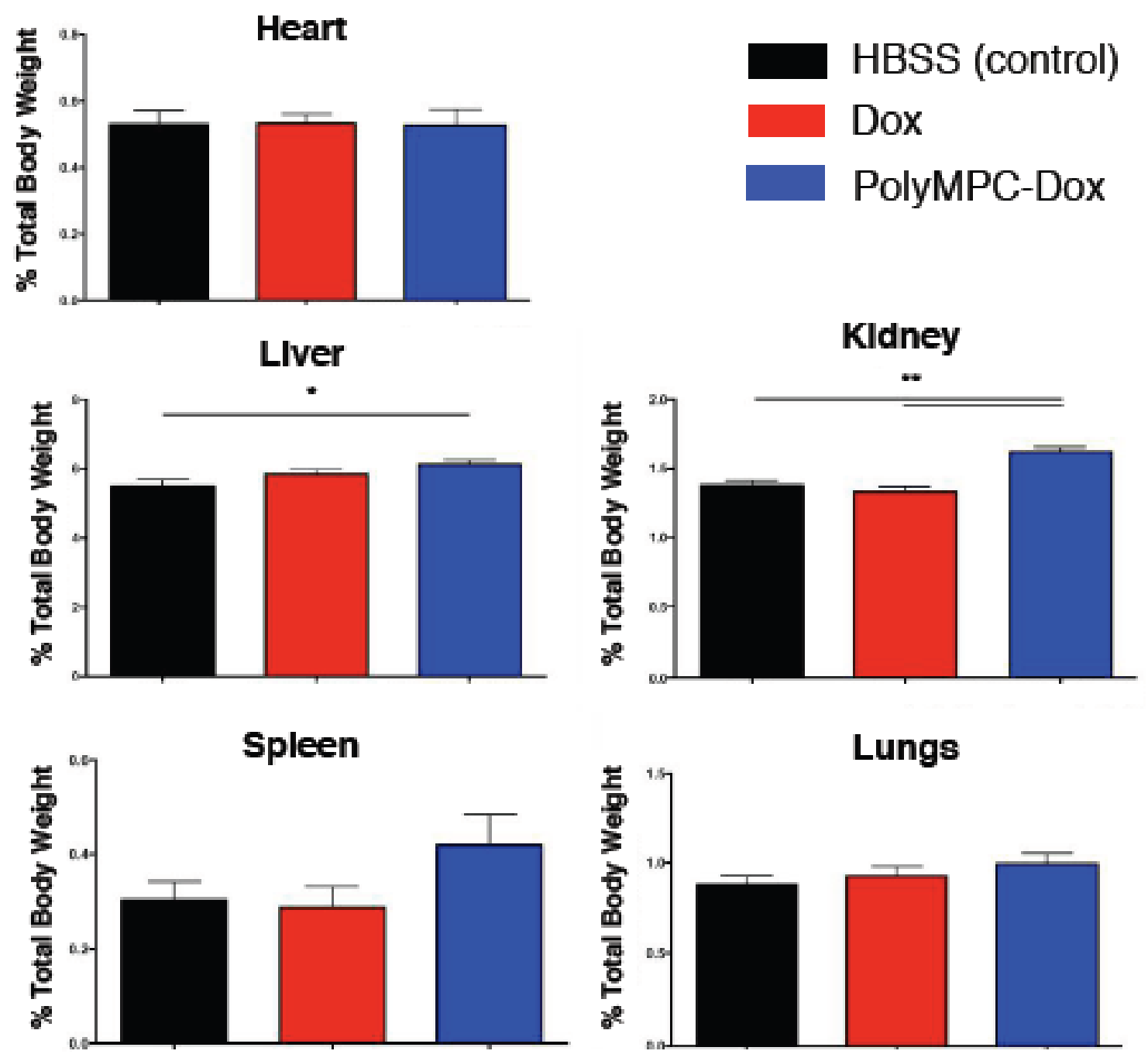

Figures S5. Proportional organ weights at time of euthanasia for NOD SCID mice, bearing subcutaneous SKOV-3 human ovarian tumors, treated with multiple administrations of HBSS (control), Dox (2 mg/kg), or polyMPC-Dox $3(5 \mathrm{mg} / \mathrm{kg}$ Dox equivalent dose). $*$ and $* *$ represent statistically significant differences at $\alpha=0.05$ and $\alpha=0.01$, respectively. Error bars represent \pm SEM. 